\title{
Performance of Solar Concentrator with and without Mirror Coating Paper
}

\author{
Agustami Sitorus ${ }^{1,2}$, Muhamad Muslih ${ }^{3}$, Oscar Haris², \\ Dewi Sartika Thamren ${ }^{4}$, and Ramayanty Bulan ${ }^{5, *}$
}

${ }^{I}$ Research Center for Appropriate Technology, National Research and Innovation Agency, Indonesia

${ }^{2}$ Department of Mechanical Engineering, Nusa Putra University, Indonesia

${ }^{3}$ Department of Information System, Nusa Putra University, Indonesia

${ }^{4}$ Department of Civil Engineering, Nusa Putra University, Indonesia

${ }^{5}$ Department Agriculture Engineering, Syiah Kuala University, Indonesia

\section{("Corresponding author's e-mail: ramayantybulan@gmail.com)}

Received: 22 September 2020, Revised: 11 April 2021, Accepted: 22 April 2021

\begin{abstract}
The utilization of solar energy continues to be developed to get the best efficiency. This energy can be used for electricity generation, cooling, and/or drying. One technology that is still under development is the use of solar concentrators. Therefore, our paper aims to measure the performance of the development of a solar collection unit coated with mirror paper. Furthermore, the data is compared with the test data for solar concentrators without mirror paper that was carried out by previous researchers in 2019. The method used in this research is a field experiment. A simple statistical comparison method was carried out on the experimental data. Field testing was conducted after the solar concentrator was coated with mirror paper. The test was carried out for 5 days in full shining sun conditions in Sukabumi Regency, Indonesia. The surface coating of the solar concentrator with mirror paper has not been able to improve the performance of the solar concentrator satisfactorily. Solar concentrators can heat the fluid from its initial average temperature of $19.37 \%$.
\end{abstract}

Keywords: Appropriate technology, Energy, Heating, Mirror coating paper, Solar concentrator

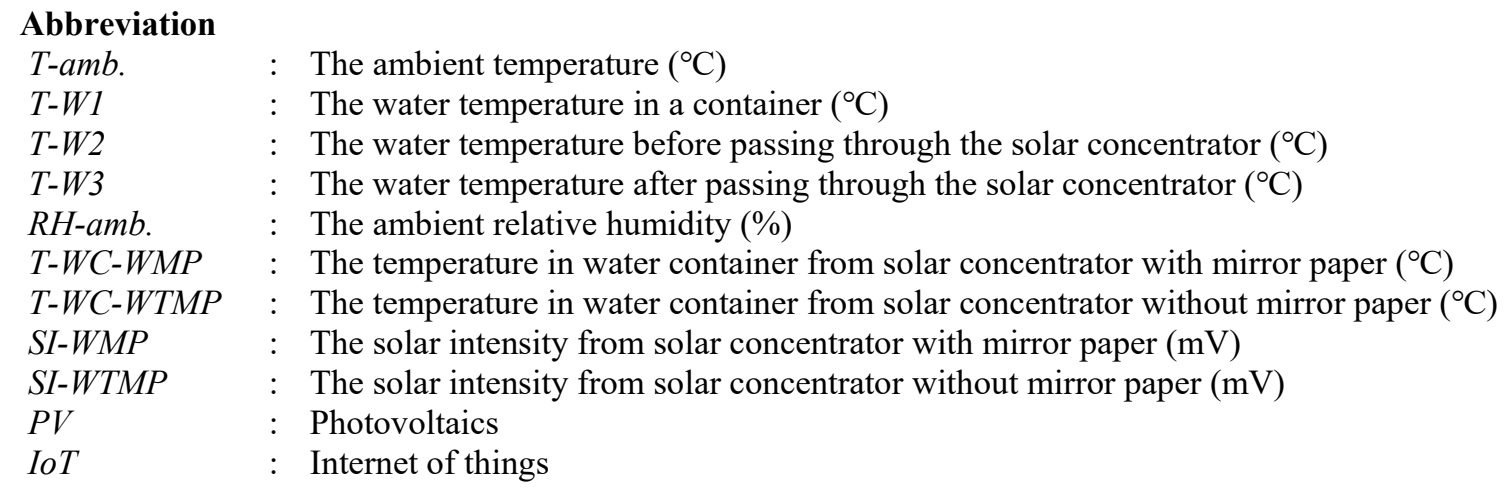

\section{Introduction}

Solar concentrator technology has continued to develop rapidly in recent years. Some of its uses have also almost entered the production phase by the industry for various purposes such as power generation [1-3], cooling [4-6] and/or drying [7-9]. Its use is also not limited to land [1,4,7], but studies have also been carried out underwater [10].

On the one hand, the application of solar concentrator technology has been integrated with PV, as has been done by several researchers [1-3] which convert solar energy into electrical energy. However, its utilization still does not open another point of view, such as the direct use of solar concentrator technology for the daily life of a community. This aims to make solar concentrators an appropriate 
technology that can be used sustainably in remote areas far from electricity sources. On the other hand, Liang et al. [10] have developed the use of underwater solar concentrators to generate electricity through the use of PV. The concept he developed is referring to the use of a solar concentrator in the sea so that it can generate electricity. But unfortunately, the results of this study report that the depth and turbidity of water will affect the PV efficiency.

One of the parameters of solar concentrator application to be an appropriate technology is the ease with which the technology can be adapted and or even replicated by a community so that it can be used sustainably $[11,12]$. It requires the use of local raw materials in the design so that the technology can be developed. One material that is very easy to find in this research location is mirror paper. This material is thought to be able to reflect sunlight to the point of the solar concentrator pipe so that it can generate heat. Therefore, this paper describes the results of measuring the performance of solar concentrators whose surface is coated with mirror paper. The results of these measurements are then compared with the results of previous studies to provide an overview of the performance of the solar concentrator.

\section{Materials and methods}

A prototype of solar concentrator

The solar concentrator used in this study is the result of the development of research by Sitorus et al. [13]. This unit consists of 3 main parts, namely the solar concentrator unit, the data logger instrument unit with the sensor and the water container unit and the circulation pump (Figure 1). This solar concentrator unit has been integrated with a measurement system based on the internet of things (IoT). Measurement data can be monitored and downloaded via the link ttgotomasi.id/ats/scnsp/gui.php.

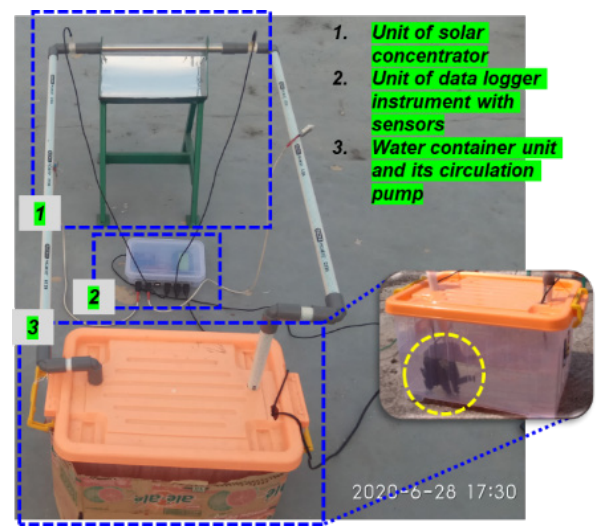

Figure 1 The main parts of a solar concentrator.

The material used to coat the surface of the solar concentrator is mirror paper, as shown in Figure 2. The mirror paper is obtained from a local market in the Sukabumi district, Indonesia. The mirror paper is combined with the surface of the solar concentrator by gluing it with paper adhesive glue. The assembly process was attempted so that the mirror paper could still follow the surface pattern of the solar concentrator.

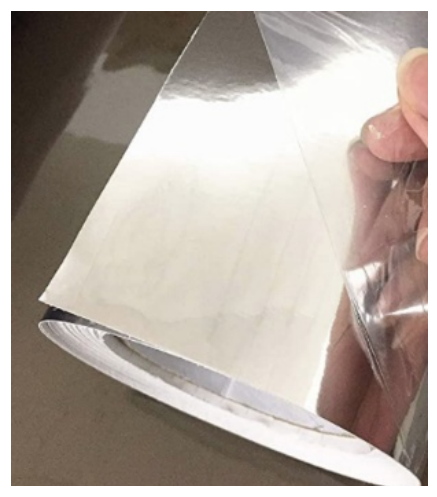

Figure 2 Mirror paper used [14]. 


\section{Solar concentrator performance testing procedure}

The performance test of the solar concentrator was carried out after the surface of the solar concentrator was coated with mirror paper. The experiment was carried out for 5 consecutive days in sunny weather conditions. A data logger measuring instrument has been designed with 3 points for measuring fluid temperature, 1 point for measuring temperature and environment, and 1 point for measuring solar intensity. The temperature sensor used at the fluid measurement point is the DS18B20 digital thermometer type. The temperature and humidity sensor used is the DHT22 digital thermometer. The solar intensity sensor used is the LDR sensor module. The measurement points on the solar concentrator are presented in Figure 3. All measurement data are sent via the internet network to the cloud database. This data can be accessed via the http://ttgotomasi.id/ats/scnsp/gui.php.

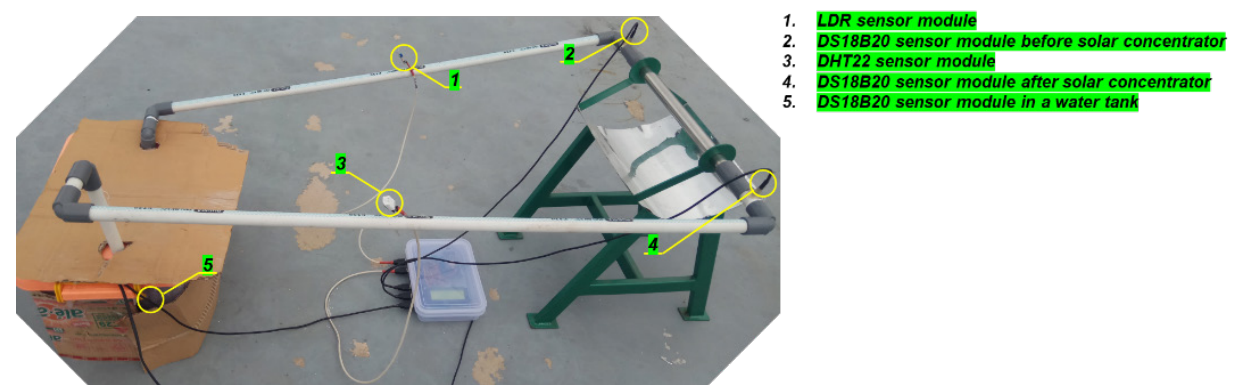

Figure 3 Measuring points in the solar concentrator.

The solar concentrator unit is combined with a fluid container filled with water. This fluid was chosen because it is more stable in storing heat. The amount of fluid used is $0.012 \mathrm{~m}^{3}$. Furthermore, the fluid is pumped into the solar concentrator and returns to the fluid storage container. This circulation takes place during field testing. The initial measurement of water temperature before testing is carried out every day. Testing was carried out by a field laboratory at Nusa Putra University, Sukabumi, West Java, Indonesia (6 $\left.6^{\circ} 4^{\prime} 17.9^{\prime \prime S} 106^{\circ} 52^{\prime} 24.1^{\prime \prime E}\right)$ at $576 \mathrm{~m}$ above the sea level.

\section{Results and discussion}

Performance data of the solar concentrator coated with mirror paper

In the first test, it was found that the average amount of total data that could be recorded was $67.26 \%$ of the 17,198 data that could have been stored. A total of $67.82 \%$ is data that can be recorded on parameters of temperature and humidity of the environment. A total of $67.21 \%$ is data that can be recorded from the measurement point before through the solar concentrator. As much as $66.93 \%$ is data that can be recorded from the measurement point after through the solar concentrator. As many as $66.03 \%$ of data were recorded from the measurement point in the water container. A total of $67.74 \%$ are data recorded from the point of measurement of solar intensity.

The second test results show that the average amount of total data that could be recorded was $59.48 \%$ of the 19,083 data that should have been stored. A total of $58.58 \%$ is data that can be recorded on parameters of temperature and humidity of the environment. As much as $58.57 \%$ is data that can be recorded from the measurement point before through the solar concentrator. As much as $58.57 \%$ is data that can be recorded from the point of measurement after through the solar concentrator. A total of $58.57 \%$ are data recorded from the measurement point in the water container. A total of $64.03 \%$ is data recorded from the point of measurement of solar intensity.

The third test reveals that the average amount of total data that could be recorded was $75.16 \%$ of the 18,900 data that could have been stored. A total of $76.52 \%$ is data that can be recorded on parameters of temperature and humidity of the environment. As much as $76.96 \%$ is data that can be recorded from the measurement point before through the solar concentrator. A total of $76.96 \%$ is data that can be recorded from the measurement point after through the solar concentrator. A total of $67.05 \%$ are data recorded from the measurement point in the water container. A total of $76.97 \%$ are data that are recorded from the point of measurement of solar intensity.

The last two test, it was found that the average number of total data that could be recorded was $62.06 \%$ of the 18,054 data that could have been stored. As much as $62.06 \%$ is data that can be recorded on parameters of temperature and humidity of the environment. As much as $62.06 \%$ is data that can be 
recorded from the measurement point before through the solar concentrator. As much as $62.06 \%$ is data that can be recorded from the point of measurement after through the solar concentrator. A total of $62.06 \%$ is data recorded from the measurement point in the water container. As much as $62.06 \%$ of the data are recorded from the point of measurement for solar intensity.

The last test reveals that the average number of total data that could be recorded was $57.41 \%$ of the 17,695 data that could have been stored. As much as $57.43 \%$ is data that can be recorded on parameters of temperature and humidity of the environment. As much as $57.42 \%$ is data that can be recorded from the measurement point before through the solar concentrator. As much as $57.42 \%$ is data that can be recorded from the measurement point after through the solar concentrator. A total of $57.32 \%$ were recorded data from the measurement point in the water container. A total of $57.43 \%$ are data recorded from the point of measurement of solar intensity. The summarizes of data obtained during the test is presented in full in Table 1.

Table 1 Resuming the amount of data collected during testing.

\begin{tabular}{cccccc}
\hline \multirow{2}{*}{ Testing to } & \multicolumn{5}{c}{ Amount of data recorded at the measurement point } \\
\cline { 2 - 6 } & T-abm and RH-amb. & T-W1 & T-W2 & T-W3 & SI-WMP \\
\hline 1 & 11,664 & 11,356 & 11.559 & 11,510 & 11,649 \\
2 & 11,179 & 11,176 & 11,176 & 11,176 & 12,218 \\
3 & 14,462 & 12,672 & 14,545 & 14,546 & 14,547 \\
4 & 11,205 & 11,204 & 11,204 & 11,204 & 11,205 \\
5 & 10,162 & 10,143 & 10,160 & 10,160 & 10,162 \\
\hline
\end{tabular}

\section{Testing on 24 June 2020}

The first test of the performance of a solar concentrator coated with mirror paper was on 24 June 2020 from 07:57:33 to 17:30:48 (Figure 4). The current local time in this test is GMT+7. The test duration was $9 \mathrm{~h}, 33 \mathrm{~min}, 15 \mathrm{~s}$. The initial water temperature of the experiment was $23.62{ }^{\circ} \mathrm{C}$. The highest ambient temperature and relative humidity were $34{ }^{\circ} \mathrm{C}, 99.90 \%$. It's happened at 10:51:06 and 17:30:48. The lowest ambient temperature and relative humidity were $24.30{ }^{\circ} \mathrm{C}, 60.50 \%$, respectively. It's happened at 17:29:47 and 10:51:56. The average ambient temperature and relative humidity during this test were $28.83 \pm 1.78,87.27 \pm 7.57 \%$. The highest water temperature before and after passing through the solar concentrator was $31.37,30.62{ }^{\circ} \mathrm{C}$, respectively. It's happened at 14:45:44 and 14:45:49. The lowest water temperature before and after passing through the solar concentrator is $23.38,23.25{ }^{\circ} \mathrm{C}$, respectively. It's happened at 08:01:13 and 07:57:48. The mean water temperature before and after passing through the solar concentrator pipe was $29.23 \pm 1.87,28.49 \pm 1.92{ }^{\circ} \mathrm{C}$, respectively. The highest and lowest water temperature in the container is $30.56,23.62^{\circ} \mathrm{C}$. It's happened at 14:45:32 and 07:57:58. The average water temperature in the container is $28.49 \pm 1.77^{\circ} \mathrm{C}$. The highest and lowest solar intensity on a container was $405,10 \mathrm{mV}$, respectively. It's happened at 17:30:40 and 08:06:27. Average solar intensity is $67.12 \pm 65.73 \mathrm{mV}$.

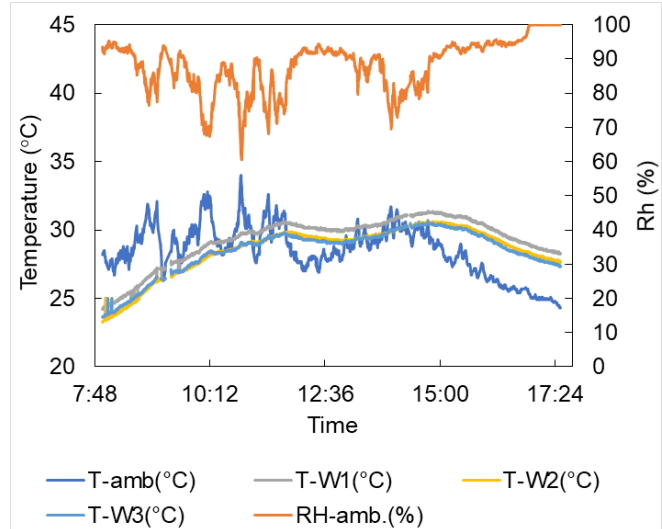

(a)

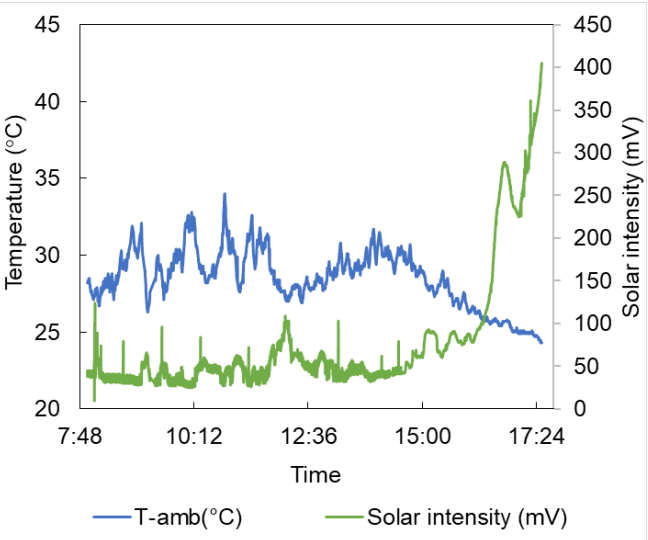

(b)

Figure 4 The first test of the performance of a solar concentrator (a) temperature and relative humidity (b) ambient temperature with solar intensity. 


\section{Testing on 25 June 2020}

The second test of the performance of a solar concentrator coated with mirror paper was on 25 June 2020 from 06:56:04 to 17:32:10 (Figure 5). The test duration was $10 \mathrm{~h}, 36 \mathrm{~min}, 6 \mathrm{~s}$. The initial water temperature of the experiment was $22.69^{\circ} \mathrm{C}$. The highest ambient temperature and relative humidity were $37.90{ }^{\circ} \mathrm{C}, 99.90 \%$, respectively. It's happened at 12:29:29 and 17:32:10. The lowest ambient temperature and relative humidity were $23.30{ }^{\circ} \mathrm{C}, 42.40 \%$, respectively. It's happened at 06:57:06 and 12:29:40. The average ambient temperature and relative humidity during this test were $31.22 \pm 3.81{ }^{\circ} \mathrm{C}, 71.20 \pm$ $18.22 \%$. The highest water temperature before and after passing through the solar concentrator was $34.88,34.25{ }^{\circ} \mathrm{C}$, respectively. It's happened at 13:41:12 and 12:34:55. The lowest water temperature before and after passing through the solar concentrator is $23.44,22.56{ }^{\circ} \mathrm{C}$, respectively. It's happened at 07:06:10 and 06:58:33. The mean water temperature before and after passing through the solar concentrator pipe was $29.08 \pm 3.75,28.25 \pm 3.83{ }^{\circ} \mathrm{C}$, respectively. The highest and lowest water temperature in the container is $34.19,22.69{ }^{\circ} \mathrm{C}$. It's happened at 12:53:58 and 07:02:36. The average water temperature in the container is $28.36 \pm 3.72{ }^{\circ} \mathrm{C}$. The highest and lowest solar intensity on a container was 428, $24 \mathrm{mV}$, respectively. It's happened at 17:31:56 and 11:44:24. Average solar intensity is $49.89 \pm 52.68 \mathrm{mV}$.

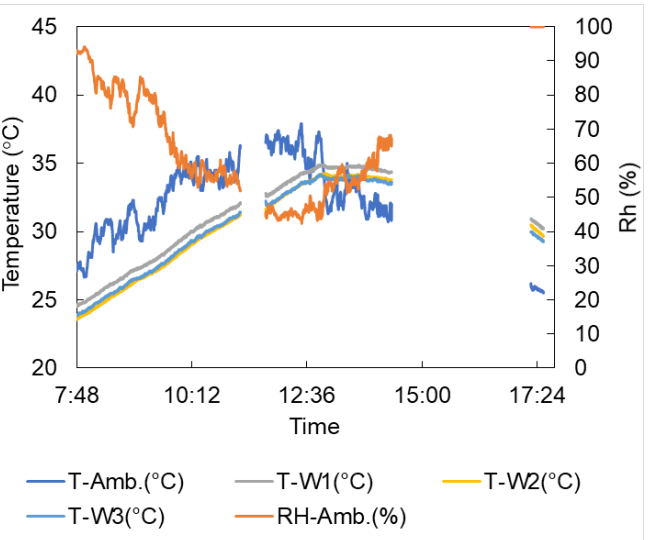

(a)

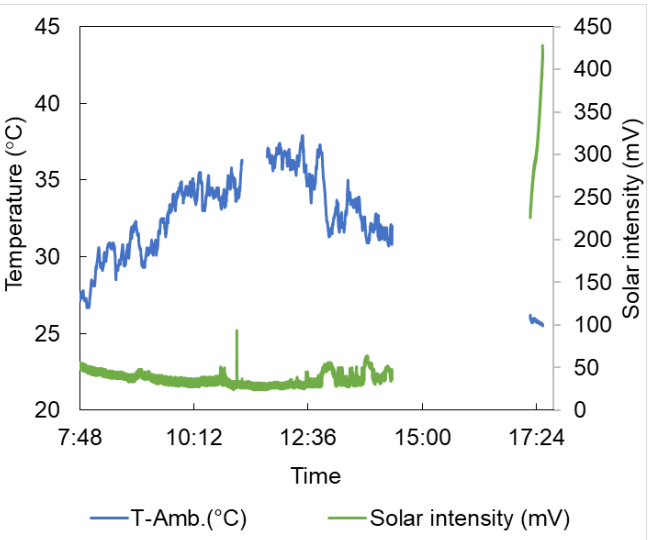

(b)

Figure 5 The second test of the performance of a solar concentrator (a) temperature and relative humidity (b) ambient temperature with solar intensity.

\section{Testing on 26 June 2020}

The third test of the performance of a solar concentrator coated with mirror paper was on 26 June 2020 from 07:00:01 to 17:30:00 (Figure 6). The test duration was $10 \mathrm{~h}, 29 \mathrm{~min}, 59 \mathrm{~s}$. The initial water temperature of the experiment was $23.12^{\circ} \mathrm{C}$. The highest ambient temperature and relative humidity were $35.90{ }^{\circ} \mathrm{C}, 99.90 \%$, respectively. It's happened at 13:12:23 and 07:12:52. The lowest ambient temperature and relative humidity were $22.40{ }^{\circ} \mathrm{C}, 54.00 \%$, respectively. It's happened at 07:00:39 and 12:29:43. The average ambient temperature and relative humidity during this test were $30.57 \pm 3.06{ }^{\circ} \mathrm{C}, 79.05 \pm 12.89$ $\%$. The highest water temperature before and after passing through the solar concentrator was 35.00, $34.31^{\circ} \mathrm{C}$, respectively. It's happened at 14:08:26 and 14:08:55. The lowest water temperature before and after passing through the solar concentrator is $23.12,23.12{ }^{\circ} \mathrm{C}$, respectively. It's happened at 07:10:58 and 07:01:07. The mean water temperature before and after passing through the solar concentrator pipe was $30.52 \pm 3.93,29.89 \pm 3.82{ }^{\circ} \mathrm{C}$, respectively. The highest and lowest water temperature in the container is $34.31,24.12{ }^{\circ} \mathrm{C}$. It's happened at 14:12:31 and 07:56:03. The average water temperature in the container is $30.78 \pm 3.07{ }^{\circ} \mathrm{C}$. The highest and lowest solar intensity on a container was $423,26 \mathrm{mV}$, respectively. It's happened at 17:30:00 and 12:28:19. Average solar intensity is $52.15 \pm 37.99 \mathrm{mV}$.

\section{Testing on 27 June 2020}

The last two test of the performance of a solar concentrator coated with mirror paper was on 27 June 2020 from 07:28:12 to 17:30:00 (Figure 7). The test duration was $10 \mathrm{~h}, 1 \mathrm{~min}, 48 \mathrm{~s}$. The initial water temperature of the experiment was $23.56{ }^{\circ} \mathrm{C}$. The highest ambient temperature and relative humidity were $36.70{ }^{\circ} \mathrm{C}, 99.90 \%$, respectively. It's happened at 11:46:29 and 08:14:01. The lowest ambient temperature and relative humidity were $23.60^{\circ} \mathrm{C}, 55.30 \%$, respectively. It's happened at 08:11:05 and 11:46:15. The 
average ambient temperature and relative humidity during this test were $29.49 \pm 3.24{ }^{\circ} \mathrm{C}, 84.43 \pm 12.41$ $\%$. The highest water temperature before and after passing through the solar concentrator was 33.88 , $33.13{ }^{\circ} \mathrm{C}$, respectively. It's happened at 12:36:20 and 12:37:02. The lowest water temperature before and after passing through the solar concentrator is $24.37,23.62{ }^{\circ} \mathrm{C}$, respectively. It's happened at 07:33:08 and 07:29:31. The mean water temperature before and after passing through the solar concentrator pipe was $29.28 \pm 3.14,28.51 \pm 3.21^{\circ} \mathrm{C}$, respectively. The highest and lowest water temperature in the container is 33.06, $23.56{ }^{\circ} \mathrm{C}$. It's happened at 13:23:28 and 07:33:31. The average water temperature in the container is $28.47 \pm 3.15{ }^{\circ} \mathrm{C}$. The highest and lowest solar intensity on a container was $346,27 \mathrm{mV}$, respectively. It's happened at 17:30:00 and 12:01:01. Average solar intensity is $60.58 \pm 47.74 \mathrm{mV}$.

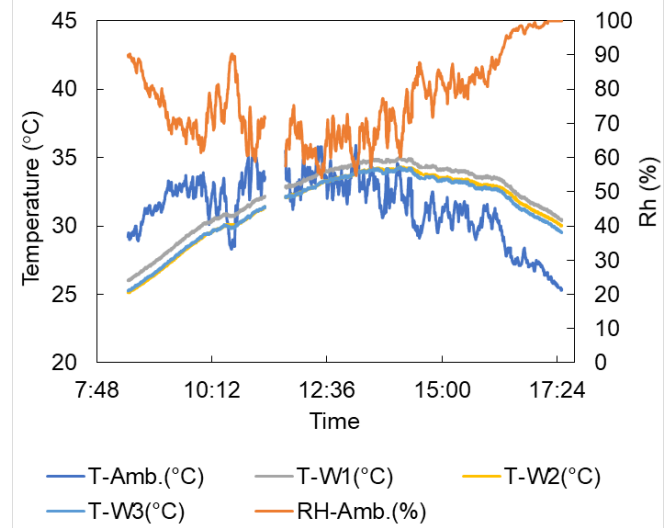

(a)

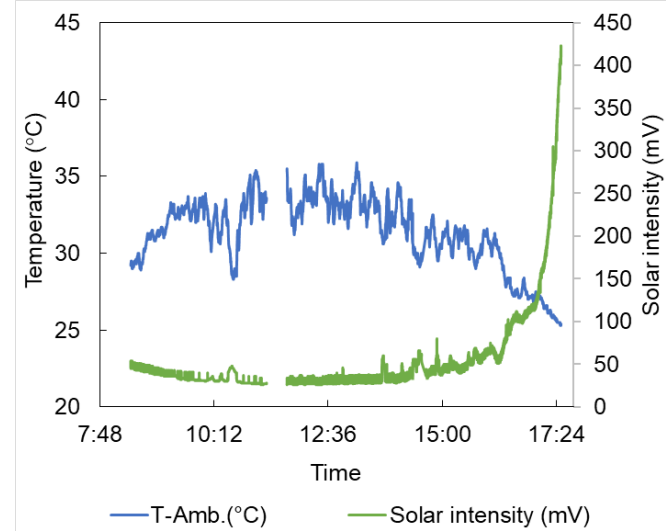

(b)

Figure 6 The third test of the performance of a solar concentrator (a) temperature and relative humidity (b) ambient temperature with solar intensity.

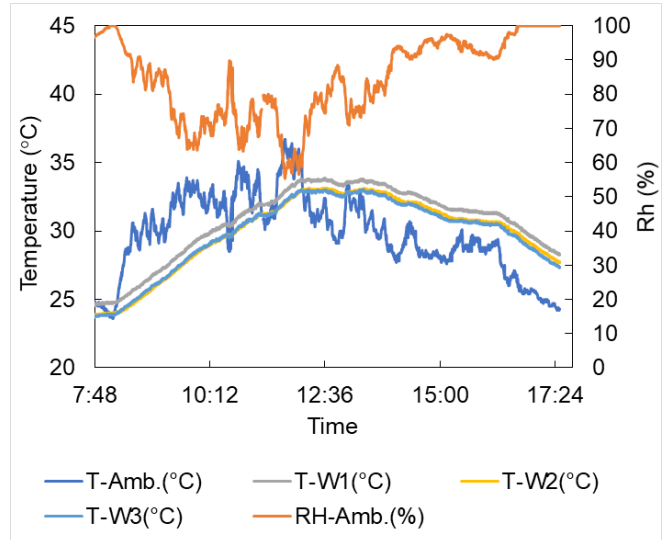

(a)

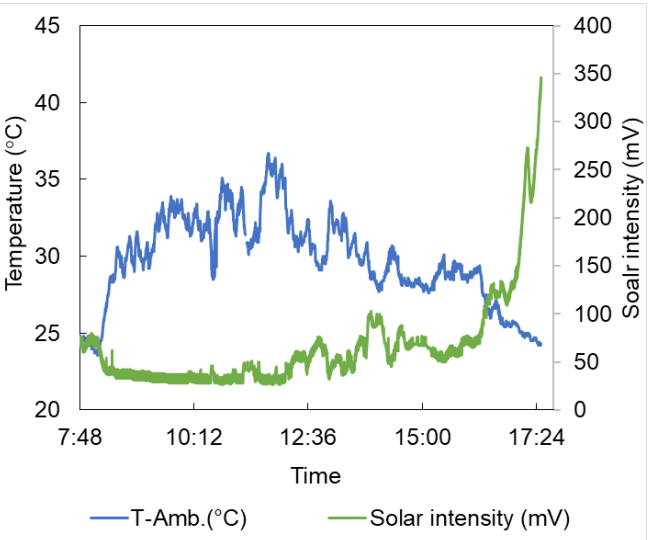

(b)

Figure 7 The last 2 test of the performance of a solar concentrator (a) temperature and relative humidity (b) ambient temperature with solar intensity.

\section{Testing on 28 June 2020}

The last one test of the performance of a solar concentrator coated with mirror paper was on 28 June 2020 from 07:40:06 to 17:29:56 (Figure 8). The test duration was 9 h, $49 \mathrm{~min}, 50 \mathrm{~s}$. The initial water temperature of the experiment was $23.75^{\circ} \mathrm{C}$. The highest ambient temperature and relative humidity were $36.20^{\circ} \mathrm{C}, 99.90 \%$, respectively. It's happened at 12:21:23 and 07:59:32. The lowest ambient temperature and relative humidity were $24.70{ }^{\circ} \mathrm{C}, 59.20 \%$, respectively. It's happened at 07:45:15 and 12:35:20. The average ambient temperature and relative humidity during this test were $30.51 \pm 2.38{ }^{\circ} \mathrm{C}, 84.47 \pm 9.36 \%$. The highest water temperature before and after passing through the solar concentrator was 34.44, 33.69 ${ }^{\circ} \mathrm{C}$, respectively. It's happened at 13:57:17 and 13:57:47. The lowest water temperature before and after passing through the solar concentrator is $23.75,22.75{ }^{\circ} \mathrm{C}$, respectively. It's happened at 07:46:29 and 
07:46:41. The mean water temperature before and after passing through the solar concentrator pipe was $29.38 \pm 3.77,29.57 \pm 3.25^{\circ} \mathrm{C}$, respectively. The highest and lowest water temperature in the container is $33.50,23.00^{\circ} \mathrm{C}$. It's happened at 13:57:24 and 08:10:28. The average water temperature in the container is $29.57 \pm 3.25^{\circ} \mathrm{C}$. The highest and lowest solar intensity on a container is $328,27 \mathrm{mV}$. It's happened at $17: 26: 26$ and 12:30:18. Average solar intensity is $55.35 \pm 33.01 \mathrm{mV}$.

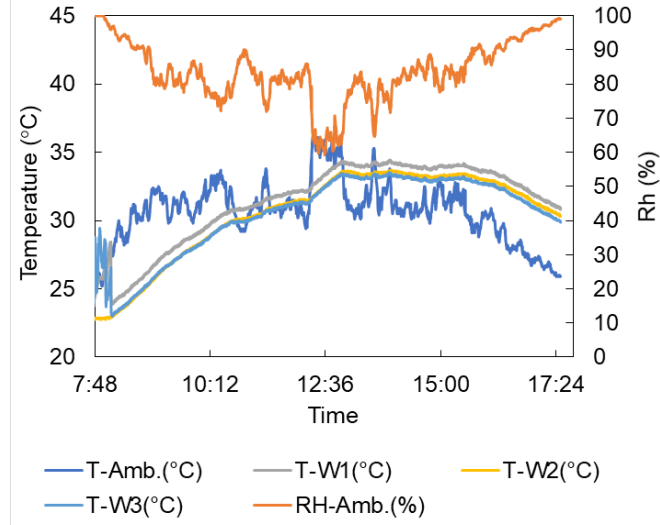

(a)

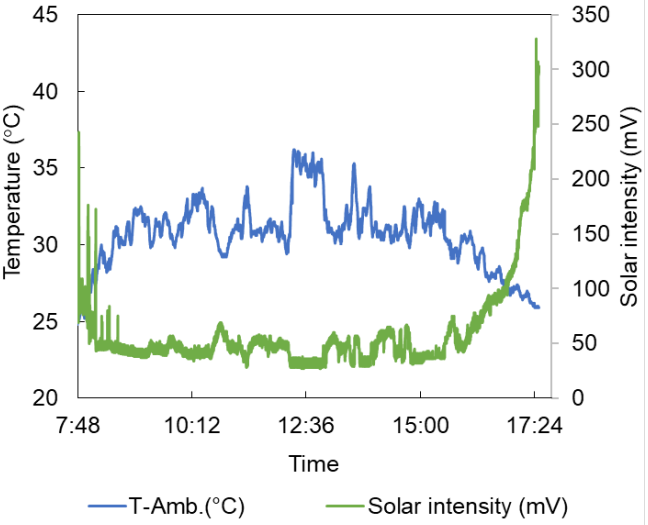

(b)

Figure 8 The last of performance of a solar concentrator (a) temperature and relative humidity (b) ambient temperature with solar intensity.

\section{Comparison of performance with and without mirror paper}

Overall, the comparison of the performance of the solar concentrator in this paper is compared with the results of the study by Sitorus et al. [13] is presented in Figure 9. It can be seen that the average solar intensity during the test conducted by Sitorus et al. [13] is lower than when tested in this paper. However, the average temperature that can be generated by the solar concentrator is $5.99 \%$ higher than the results of this study. The increase in fluid temperature in this study amounted to $19.37 \%$. This is presumably because the coating with mirror paper cannot collect solar energy maximally to the surface of the fluid flow pipe.

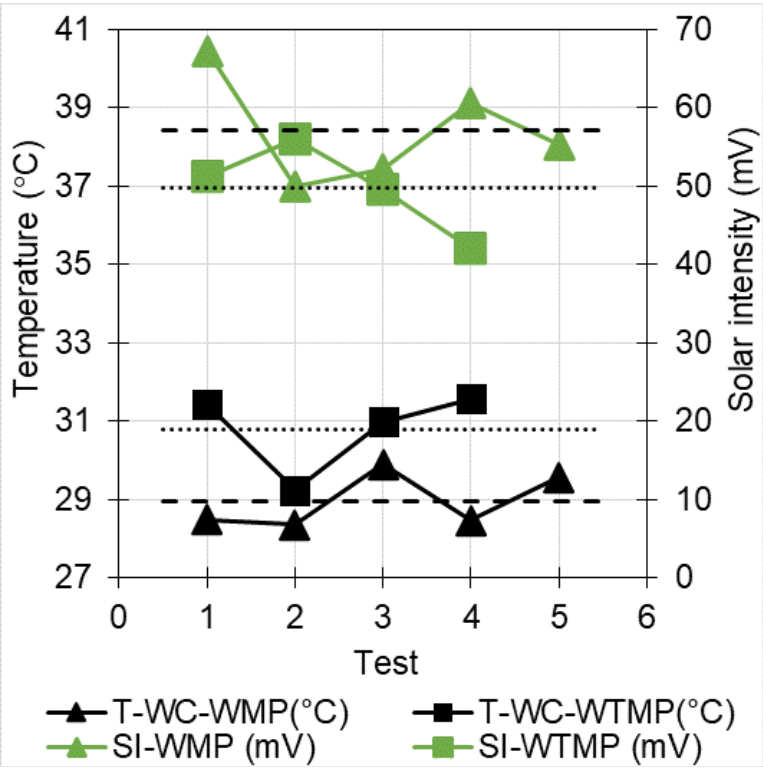

Figure 9 Performance comparison of solar concentrators with and without mirror paper. 


\section{Conclusions}

Performance measurement of the solar concentrator coated with mirror paper has been carried out. The performance analysis of the solar concentrator has also been compared with that of without mirror paper coating. Mirror paper coating does not provide a satisfactory temperature rise to the heated water container. The difference in temperature of the fluid heated with solar concentrator with and without pine paper is an average of $5.99 \%$. The increase in fluid temperature from the initial was $19.37 \%$. Therefore, this paper provides suggestions for researchers and engineers related to the development of solar concentrators to consider the use of mirror paper for solar concentrator surfaces. The future work of this research is to develop and test with a pure mirror coating which is formed according to the surface of the solar concentrator.

\section{References}

[1] Y Gu, X Zhang, JA Myhren, M Han, X Chen and Y Yuan.Techno-economic analysis of a solar photovoltaic/thermal (PV/T) concentrator for building application in Sweden using Monte Carlo method. Energ. Convers. Manag. 2018, 165, 8-24.

[2] VM Andreev, VA Grilikhes, VP Khvostikov, OA Khvostikova, VD Rumyantsev, NA Sadchikov and MZ Shvarts. Concentrator PV modules and solar cells for TPV systems. Sol. Energ. Mater. Sol. Cell 2004; 84, 3-17.

[3] G Li, Q Xuan, MW Akram, YG Akhlaghi, H Liu and S Shittu. Building integrated solar concentrating systems: A review. Appl. Energ. 2020; 260, 114288.

[4] EM Abo-Zahhad, S Ookawara, MFC Esmail, AH El-Shazly, MF Elkady and A Radwan. Thermal management of high concentrator solar cell using new designs of stepwise varying width microchannel cooling scheme. Appl. Therm. Eng. 2020; 172, 115-24.

[5] MM Ehsan, Z Guan, H Gurgenci and A Klimenko. Novel design measures for optimizing the yearlong performance of a concentrating solar thermal power plant using thermal storage and a drycooled supercritical $\mathrm{CO}_{2}$ power block. Energ. Convers. Manag. 2020; 216, 112980.

[6] A Moaleman, A Kasaeian, M Aramesh, O Mahian, L Sahota and GN Tiwari. Simulation of the performance of a solar concentrating photovoltaic-thermal collector, applied in a combined cooling heating and power generation system. Energ. Convers. Manag. 2018; 160, 191-208.

[7] M Ssemwanga, E Makule and SI Kayondo. Performance analysis of an improved solar dryer integrated with multiple metallic solar concentrators for drying fruits. Sol. Energ. 2020; 204, 41928.

[8] A Liqreina and L Qoaider. Dry cooling of concentrating solar power (CSP) plants, an economic competitive option for the desert regions of the MENA region. Sol. Energ. 2014; 103, 417-24.

[9] SM El-Bashir and AA Al-Jaghwani. Perylene-doped polycarbonate coatings for acrylic active greenhouse luminescent solar concentrator dryers. Results Phys. 2020; 16, 102920.

[10] S Liang, H Zheng, X Ma and D Cui. Design and experimental investigation on a solar concentrating photovoltaic underwater. Energy 2020; 204, 117958.

[11] CPM Sianipar, G Yudoko, K Dowaki and A Adhiutama. Design methodology for appropriate technology: Engineering as if people mattered. Sustainability 2013; 5, 3382-425.

[12] AM Bauer and A Brown. Quantitative assessment of appropriate technology. Procedia Eng. 2014; 78, 345-58.

[13] A Sitorus, AR Hasan, A Karyadi and Y Nata. Simple performance test of an appropriate technology solar concentrator equipped with a monitoring system for remote areas. Int. J. Sci. Tech. Res. 2019; 8, 3744-8.

[14] Anonymous. REDODECO Self-adhesive reflective chrome silver vinyl wrap sticker decal film sheet 12 inch by 60 inch. Anonymous, 2020. 